\title{
Reflexões mais que pertinentes
}

Marcelo Paula de Melo $^{1}$

FONTES, Virgínia. Reflexões Im-pertinentes: história e capitalismo contemporâneo. Rio de Janeiro: Bom texto, 2005. 327 p.

A formação social capitalista tem passado por intensas transformações das mais variadas naturezas nos últimos 30 anos. Tanto no plano da produção material da existência, quanto na dimensão subjetiva da apreensão das contradições e dinâmicas dessas mudanças, pode-se dizer que a atual fase do capitalismo apresenta-se de maneira absolutamente diferente de sua fase anterior. Sem deixar de assentar-se na expropriação do trabalho socialmente produzido, bem como na privatização dos mecanismos e aparelhos de decisão coletiva de organização da sociedade, a natureza e a forma de tais processos são fruto das lutas políticas e correlação de forças entre as classes e frações de classe sociais na consecução de seus projetos societários.

Tendo isso como elemento balizador, a historiadora Virgínia Fontes nos lega um livro de grande relevância para o conjunto de pesquisadores das áreas de ciências humanas. Reflexões Im-pertinentes: história e capitalismo contemporâneo reúne alguns artigos publicados em periódicos nacionais e internacionais a partir do fim dos anos 1990. Como está expresso logo na apresentação, a autora dedica sua atenção a três temáticas principais:

os rumos e os desdobramentos do capitalismo contemporâneo; as formas da política, com ênfase na relação entre o processo histórico e alguns aspectos da subjetividade que cada período contribui para formatar, compondo uma certa forma de ser no mundo e, finalmente, uma permanente interrogação sobre o caso brasileiro (p. 9).

Ao eleger essas temáticas como objeto de suas preocupações, Virginia Fontes o faz a partir de uma leitura muito própria e qualificada do marxismo. Tendo como principal interlocutor Antonio Gramsci, Fontes não procura esconder-se nas categorias e formulações de suas referências.

1 Professor do Instituto Superior de Educação da Fundação de Apoio à Escola Técnica do Estado do Rio de Janeiro - ISE/FAETEC (Rio de Janeiro, Brasil). basqueteiromelo@terra.com.br. 
A autora defende que o marxismo não pode ser considerado uma disciplina à parte, e que não se configura como um campo de estudos que se esgotaria em si próprio, mas que é, sim, um terreno que demanda um permanente exercício de pensar a realidade a partir das contradições postas pelo mundo real. Com isso, postula que o espaço ocupado pelo marxismo nutre-se do debate, da polêmica, mas, sobretudo, do rigor e reflexão sistemática sobre a realidade. São interlocuções obrigatórias não apenas a produção no interior dessa vertente filosófica, mas também, e principalmente, as críticas formuladas e as vertentes que ao marxismo se opõem. Fontes afirma que "a teoria marxista supõe - e exige - o debate filosófico, não por mera erudição, não por mero gosto da teoria pela teoria, mas por considerar que o conhecimento não se deve deixar aprisionar pelas frases feitas, pela retórica retumbante, pela última moda" (p. 10).

A questão democrática e as condições históricas que possibilitam sua ampliação ou encolhimento - como parece ser a do nosso tempo são panos de fundo que orientam o conjunto dos artigos dispostos no livro. Como a própria autora deixa claro, sua análise da democracia não se limita a considerá-la como o lugar da política, reduzindo-se unicamente à formação de governos, mesmo que isso se dê numa conjuntura fundada na exploração e na desigualdade.

Em muitos capítulos, Fontes apresenta a tese de ampliação seletiva do Estado capitalista brasileiro. Divergindo de outros autores, como Carlos Nelson Coutinho e Marco Aurélio Nogueira, Virgínia defende, a partir de Antonio Gramsci, que o Estado brasileiro ampliou-se de forma seletiva, principalmente a partir dos anos 1930. Isso significa que as classes dominantes, em que pesem os conflitos intraclasse, já atuavam politicamente na sociedade civil através de suas associações, caracterizando uma sociedade ocidental em termos gramscianos, e que buscava difundir suas concepções de mundo e projetos de sociedade, penetrando, assim, no seio do aparelho estatal.

O livro é organizado em duas seções. Na primeira, intitulada "Pensar o capitalismo hoje: economia, política e modo de ser", Virgínia Fontes se dedica a compreender as principais questões afeitas ao capitalismo contemporâneo, bem como os aspectos históricos que contribuíram e influenciaram no processo, e o faz fielmente ao marxismo de Gramsci, tentando superar a fragmentação artificial e estanque da vida social em economia, política, cultura e sociedade, já que esse tipo de cisão corresponderia a uma concepção de mundo que naturaliza as relações 
sociais capitalistas. Lançando mais luz sobre essa premissa metodológica de um marxismo realmente fiel à tradição iniciada pelo autor de O Capital, atualizada por autores como Gramsci, Poulantzas E. P. Thompson, dentre outros, Fontes alerta:

Aceitar sua fragmentação como blocos estanques é perder de vista o quanto essa separação resulta de processos sociais hoje dominantes e como implica uma redução drástica de nossa capacidade de nos percebermos no mundo. Essa separação fictícia resulta numa quase amputação de nossa capacidade de compreender o mundo em que vivemos, amputação que incide sobre o próprio sentido de nossas existências (p. 14-15).

Esta primeira parte do livro é dividida em cinco capítulos. No primeiro, intitulado "Capitalismo, exclusões e inclusão forçada", Fontes se dedica a apresentar a trajetória teórica do conceito de exclusão. A partir disso, defende com muita propriedade que o capitalismo desde o início provoca "inclusões forçadas" no mercado, cuja expressão central é a mercantilização dos trabalhadores, sob a forma de assalariamento de sua força de trabalho, e que só através dela conseguiriam sua reprodução material e social.

Por outro lado, Fontes sustenta que a partir dos anos 1970 o capitalismo deixa de incluir forçadamente uma parcela da população. Se em outro momento a necessidade de inclusão nas relações sociais capitalistas era condição para o aumento das taxas de lucro, com a financeirização do capital isso se torna secundário, tornando uma parcela da população descartável ao capital. A isso Fontes chamou de exclusão externa.

Nos dois capítulos ulteriores, a autora se debruça sobre a especificidade e generalização do trabalho abstrato na atualidade. No capítulo dois, "O trabalho abstrato e a cultura contemporânea, ou os desafios atuais do pensamento histórico", escrito na forma de um "bate-bola" com Stefano Garroni sobre sua análise da obra do escritor Émile Zola, o foco centrase na compreensão da natureza da subsunção cada vez maior do trabalho ao capital, e as conseqüências disso para a sociabilidade contemporânea. Já no capítulo três, cujo título é "As condições históricas e sociais da generalização do trabalho abstrato: permanência e transformação das formas de expropriação", o objetivo central é aprofundar a discussão acerca da subsunção formal do trabalho ao capital, enfatizando sobretudo as mudanças históricas nos processos de expropriação do trabalho socialmente 
produzido. Isso se daria através da ampla disseminação do trabalho abstrato em detrimento do trabalho produtivo.

No capítulo quatro, "As expropriações contemporâneas e o papel da política", encontramos um debate necessário no âmbito dos estudos marxistas da política. Nesse capítulo, Virgínia procura romper com qualquer tendência economicista. Para isso, apresenta as maneiras como as formas de expropriação e subsunção do trabalho ao capital não podem de forma alguma ser reduzidas às dimensões econômicas, como se essas tivessem vida própria. Fontes defende também que o capital provoca uma expropriação da subjetividade ao suscitar, mesmo em suas críticas internas das relações sociais, valores que lhe são caros como o da produtivização, o da crença irrestrita no progresso e o da naturalização, como algo dado, das relações sociais capitalistas. Não obstante, a naturalização de uma situação de desemprego e precarização em massa tende a introjetar em cada trabalhador o elemento de competição com seu colega, conjugado com a mercantilização das mais variadas esferas da vida. Longe de ser uma dimensão apenas econômica, isso se apresenta como a nova face do capitalismo mundial.

No capítulo 5, "Historicidade e subjetividade: contradições e conflito, liberdade e determinação", temos um debate muito rico e erudito, que Fontes se propõe a realizar entre a concepção freudiana de CONFLITO e a categoria marxista de CONTRADIÇÃO. Visa, com isso, perceber possíveis contribuições para pensarmos nosso tempo e os limites e possibilidades da luta política a partir deste debate. No segundo momento, enfrenta de forma dialética a relação entre liberdade e determinação, vistas na forma das possibilidades encontradas pelo sujeito social em seu tempo, mas considerando as limitações que esse mesmo tempo impõe a esse sujeito.

$\mathrm{Na}$ segunda parte do livro, "Brasil contemporâneo: nação, poder e cultura", Virginia apresenta cinco capítulos que têm como eixo central a especificidade do caso brasileiro e que abarca um período histórico que vai do século XIX (cap. 6) até nossos dias (cap. 10). O tema central que orienta tais estudos é o de como se deu o processo de incorporação do Brasil ao capitalismo, bem como o das resistências e movimentos das classes sociais e suas frações nessa luta política.

No capítulo 6, "A nação hierárquica: um ensaio sobre o Brasil no século XIX", temos um debate acerca da constituição da relação Estado e sociedade (civil) no Brasil e uma polêmica acerca das interpretações de 
que no Brasil o Estado dominaria e encastelaria a sociedade, sendo ele (o Estado) o indutor das relações sociais. Fontes sustenta que tais concepções situam o Estado acima das relações sociais, como portador de uma vontade própria, abstraído das lutas e embates políticos entre as classes e frações de classe. É a noção de Estado "sujeito". Já no sétimo capítulo, “Ampliação do Estado e coerção no Brasil, democratização e nacionalização truncada (o DIP e modelo de violência seletiva)", o foco central é o lugar ocupado pela propaganda e pela publicidade na sedimentação do consenso instaurado na ditadura do Estado novo. Pode-se dizer que a partir daí inaugura-se uma nova forma de atuar das classes dominantes na consecução de seus objetivos. Instaura-se a necessidade de busca e de consolidação do consenso popular, indicando que apenas a repressão não seria suficiente. Conjugando isso à ampliação seletiva do Estado, Fontes demonstra como o Departamento de Imprensa e Propaganda (DIP), ao mesmo tempo que censurava determinadas produções, impulsionava outras. No capítulo seguinte, "Que hegemonia? Peripécias de um conceito no Brasil", encontra-se um rico debate acerca das interpretações da história do Brasil a partir do conceito gramsciano de hegemonia. Fundamental para compreendermos o caso brasileiro, esse capítulo traz a polêmica de que, longe de ter havido realmente uma crise de hegemonia, tivemos no Brasil muitos momentos históricos de rearranjo das classes dominantes a partir de disputas intraclasse, como, por exemplo, os eventos ocorridos nos anos 1930. Ainda que tenha havido momentos de intensas disputas, não se pode afirmar que a hegemonia da classe dominante tenha sido amplamente abalada. Outra grande contribuição presente nesse capítulo é a discussão acerca da relação entre estado e hegemonia no Brasil, tendo como interlocutores principais Sonia Regina de Mendonça e Carlos Nelson Coutinho.

O nono capítulo apresenta a trajetória de Chico Buarque de Holanda e faz a relação de sua produção política. Aqui, a temática central é o pensamento sobre as possibilidades de se pensar historicamente a relação cultura e política no Brasil. E, por último, mas não menos importante, o capítulo 10 - "A política e arte da desqualificação" - traz um debate absolutamente relevante para o atual momento. Fontes analisa a trajetória do Partido dos Trabalhadores (PT) em seus 26 anos de existência. Nesse processo, identifica como o PT nos seus 10 primeiros anos representou no cenário político brasileiro uma luta dos setores à esquerda para requalificar a política. Isso representava uma atuação onde a organização dos setores populares precedia à conquista de cargos e a disputa eleitora 
per se. Implicava também numa série de perseguições e acusações por partes dos setores dominantes. Por outro lado, Fontes demonstra como o PT acabou elegendo como tarefa principal entrar fundo na disputa eleitoral, em detrimento de sua tarefa organizativa da sociedade. O que significou, muitas vezes, acatar as "regras do jogo" que contribuíam para desqualificar a política, regras tais como negociatas, loteamento de cargos e alianças políticas completamente antagônicas aos supostos projetos e grupos representativos.

À guisa de conclusão, podemos afirmar que a obra de Virginia Fontes representa uma grande contribuição ao campo da educação, sobretudo aos estudos de política educacional. A radicalidade do pensamento e a fidelidade ao marxismo nesse caso não significa nenhum engessamento dogmático, mas sim uma firmeza política, expressa na capacidade de analisar a realidade.

Recebido em: 08/07/2006

Aprovado em: 26/07/2006 